\title{
BMJ Open Longitudinal trends in use of targeted therapies for treatment of malignant neoplasms of the eye: a population- based study in Taiwan
}

\author{
Jason C Hsu, ${ }^{1}$ Luis A Gonzalez-Gonzalez, ${ }^{2}$ Vicky H Lu, ${ }^{3}$ Christine $\mathrm{Y} \mathrm{Lu}{ }^{4}$
}

To cite: Hsu JC, GonzalezGonzalez LA, Lu VH, et al. Longitudinal trends in use of targeted therapies for treatment of malignant neoplasms of the eye: a population-based study in Taiwan. BMJ Open 2016;6: e010706. doi:10.1136/ bmjopen-2015-010706

- Prepublication history and additional material is available. To view please visit the journal (http://dx.doi.org/ 10.1136/bmjopen-2015010706).

Received 14 December 2015 Revised 15 April 2016 Accepted 3 May 2016

CrossMark

\begin{abstract}
${ }^{1}$ School of Pharmacy and Institute of Clinical Pharmacy and Pharmaceutical Sciences, College of Medicine, National Cheng Kung University,

Tainan City, Taiwan

${ }^{2}$ Department of

Ophthalmology, Harvard

Medical School, Cambridge, Massachusetts, USA

${ }^{3}$ Sydney Eye Hospital,

Sydney, New South Wales, Australia

${ }^{4}$ Department of Population Medicine, Harvard Medical School and Harvard Pilgrim Health Care Institute, Boston, Massachusetts, USA
\end{abstract}

\section{Correspondence to}

Dr Jason C Hsu;

jasonhsuharvard@gmail.com

\section{ABSTRACT}

Objectives: This study examined the recent trend in use and costs of antineoplastic agents for treatment of eye malignancies in Taiwan from 2009 to 2012. We also forecasted use and costs of targeted therapies up to and including year 2016 based on the current patterns.

Design: Retrospective observational study focusing on the usage of targeted therapies for treatment of eye malignancy.

Setting: The monthly claims data for eye malignancyrelated antineoplastic agents were retrieved from Taiwan's National Health Insurance Research Database (2009-2012).

Main outcome measures: We calculated the number of prescriptions and costs for each class of medications, and analysed their time trends. In addition, using a time series design with ARIMA models, we estimated the market share by prescription volume and the proportion of costs for targeted therapies for year 2016.

Results: The market share by prescription volume of targeted therapies grew from $1.56 \%$ in 2009 to $9.98 \%$ in 2012 among all antineoplastic agents, and the proportion of costs for targeted therapies rose from $15.12 \%$ in 2009 to $58.88 \%$ in 2012 . Especially, the proportion of costs for protein kinase inhibitors grew from $25.62 \%$ to $45.28 \%$ among all antineoplastic agents between 2010 and 2012 . The market share by prescription volume and the proportion of costs for targeted therapies for treatment of eye malignancies were predicted to reach $27.33 \%$ and $91.39 \%$ by the fourth quarter in 2016, respectively.

Conclusions: This is the first study that examined and forecasted use and costs of targeted therapies for treatment of eye malignancies in Taiwan. Our findings indicate that, compared with other classes of drugs, targeted therapies are having a more and more relevant share among all treatment strategies for eye malignancies in Taiwan, and due to their high costs they are likely to cause great economic burden.

\section{INTRODUCTION}

Eye malignancy is the most serious disease of the eye. ${ }^{1} 2$ The incidence of eye cancers in

\section{Strengths and limitations of this study}

- This study is the first of its kind that assessed the current trend in use and expenditures of medications for treatment of eye malignancies in Taiwan from 2009 to 2012, and forecasted the use and costs of targeted therapies based on the current patterns.

- Data were retrieved from Taiwan's National Health Insurance Research Database with nearly $99 \%$ of the Taiwanese population (around 23 million residents) enrolled, and $97 \%$ of hospitals and clinics throughout the country.

- A time series design with ARIMA models was used to estimate the trends in market shares by prescription volume and costs of targeted therapies.

- Limitations include lack of complete information regarding the diagnosis of specific eye cancer classification.

the Western populations ranged from 5.4 to 8.1 per million people, and from 1.81 to 2.57 per million in East Asians. ${ }^{3}$ In Taiwan, the average annual age-standardised incidence of eye cancers was 2.46 per million population, and retinoblastoma was identified as the most common eye malignancy in this Chinese population, while melanoma is the most common eye malignancy in Western populations. $^{3-5}$

Except radiation and surgery, which are potential treatments for ophthalmic malignancies, chemotherapy is used most commonly to treat a multitude of eye cancers. ${ }^{6-11}$ In certain cases, together with radiation and surgery, chemotherapy may reduce the size of a tumour, and it may also be used to reduce morbidity and improve efficacy. ${ }^{11}$ Recently, superselective chemotherapy and targeted therapies are being used for treatment of eye malignancies. ${ }^{12-18}$

Over the last few years, several studies have examined the epidemiology of eye cancers in 
Taiwan. Cheng et al (2004) identified 733 cases with primary eye cancers by using Taiwan's National Cancer Registry, and described the incidence and histological patterns of eye cancers in Taiwan from 1979 to 1996. They found that the time trend in the incidence of eye cancers was relatively stable in Taiwan, and retinoblastoma, melanoma and lymphoma were the three most common eye cancers in this Chinese population. ${ }^{3}$ A study by Chen $e t a l^{19}$ examined the incidence and survival rate of patients with retinoblastoma in Taiwan from 1979 to 2003, and found that there was a significant increase in incidence over the study period with an increasing 5-year survival rate.

While previous studies have examined the incidence of eye cancers, and the incidence in trend over time in Taiwan, little is known about the usage and costs of treatments for eye malignancies. Our study aimed to address the above gaps by assessing the current trend in use and expenditures of medications for treatment of eye malignancies in Taiwan from 2009 to 2012. Especially, we focused on targeted therapies. These drugs differ from standard chemotherapy in that they interfere with specific molecular targets that are involved in the growth, progression and spread of cancer; thus, they are generally less toxic than traditional chemotherapies. ${ }^{20}$ Targeted therapies come with a high price tag (many cost around US\$5000 per patient per month) compared with conventional drugs. ${ }^{21-23}$ While the number of eligible patients is generally small for cancer treatment, in aggregate their costs are becoming a major contributor of growing expenditures of cancer treatments. ${ }^{24-26}$ Further, despite the high prices, some agents offer limited benefits over existing treatments. ${ }^{21-23}{ }^{27-29} \mathrm{We}$ also forecasted the use and costs of targeted therapies based on the current patterns.

\section{METHOD}

\section{Data sources}

This study used claims data from Taiwan's National Health Insurance Research Database. The database includes information from a nationwide, mandatory enrolment and single-payer healthcare system created in 1995. Nearly all of the Taiwanese population (around 23 million residents) is enrolled, and this system contracts with $97 \%$ of hospitals and clinics throughout the country. ${ }^{30}$ The National Health Insurance covers a wide range of prescription medicines, inpatient and outpatient medical services. ${ }^{31}$ We obtained, nationwide, the monthly claims data for eye malignancy-related antineoplastic agents between 2009 and 2012 from the Taiwan National Health Insurance Research database. The eye malignancy-related prescriptions were defined as those with International Classification of Diseases, 9th edition (ICD-9) diagnosis code 190.x (subsuming malignancies of eyeball, orbit, lacrimal gland, conjunctiva, cornea, retina, choroid, lacrimal duct, other specified sites of the eye and unspecified parts of eye, while not including cancers of the eyelids). This data source has been used in previous studies. ${ }^{32} 33$

\section{Drugs of interest}

We used the Anatomical Therapeutic Chemical classification system of WHO, and identified prescription drugs with first three codes- "L01" to identify claims for antineoplastic agents. We grouped antineoplastic agents into six classes: (1) targeted therapies (including monoclonal antibodies, protein kinase inhibitors and other antineoplastic agents). Some targeted therapies (rituximab, gefitinib, erlotinib, sunitinib, bortezomib) have been used for the treatment of eye malignancies in Taiwan; (2) alkylating agents (including nitrogen mustard analogues, nitrosoureas and other alkylating agents); (3) antimetabolites (including folic acid analogues and pyrimidine analogues); (4) plant alkaloids and other natural products (including vinca alkaloids and analogues, podophyllotoxin derivatives and taxanes); (5) cytotoxic antibiotics and related substances (including actinomycines, anthracyclines and related substances and other cytotoxic antibiotics) and (6) other agents (platinum compounds).

\section{Measurements}

To examine the trend in drug usage and expenditure of eye malignancy-related antineoplastic agents, we calculated the quarterly and yearly number of prescriptions and costs for each group of antineoplastic agents from 2009 to 2012. For each class, we then calculated market share by prescription volume (eg, number of prescriptions for targeted therapies divided by total number of prescriptions for all antineoplastic agents) and proportion of costs (eg, costs of targeted therapies divided by total costs of all antineoplastic agents). We converted costs in Taiwan dollars to US dollars by 30:1.

\section{Statistical analysis}

We used a time series design with the Autoregressive Integrated Moving Average (ARIMA) model to predict the market share by prescription volume and proportion of total costs for targeted therapies among all antineoplastic agents. ${ }^{34}$ The model is generally referred to as an $\operatorname{ARIMA}(p, d, q)$ model where parameters $p, d$ and $q$ are non-negative integers that refer to the order of the autoregressive, integrated and moving average parts of the model, respectively. These models are fitted to time series data either to better understand the data or to predict future points in the series. ${ }^{35}$ Based on the trend between 2009 and 2012, we predicted the quarterly market share by prescription volume and quarterly proportion of costs for targeted therapies from 2013 to 2016. All analyses were carried out with SAS software, V.9.3 (SAS Institute, Cary, NC). We used similar measurements and analytical methods previously. ${ }^{32} 333637$ 
Table 1 Trends in market share by prescription volume of antineoplastic agents for eye cancer in Taiwan by drug class

\begin{tabular}{|c|c|c|c|c|c|c|c|c|c|}
\hline \multirow[b]{3}{*}{ Drug class } & \multirow[b]{3}{*}{ Drug names } & \multicolumn{8}{|c|}{ Number of prescriptions } \\
\hline & & \multicolumn{2}{|c|}{2009} & \multicolumn{2}{|l|}{2010} & \multicolumn{2}{|l|}{2011} & \multicolumn{2}{|l|}{2012} \\
\hline & & Volume & (\%) & Volume & $(\%)$ & Volume & $(\%)$ & Volume & $(\%)$ \\
\hline $\begin{array}{l}\text { All antineoplastic } \\
\text { agents }\end{array}$ & & 707 & 100.00 & 832 & 100.00 & 741 & 100.00 & 634 & 100.00 \\
\hline Targeted therapies & & 11 & 1.56 & 41 & 4.93 & 32 & 4.32 & 64 & 10.09 \\
\hline $\begin{array}{l}\text { Monoclonal } \\
\text { antibodies }\end{array}$ & Rituximab & 11 & 1.56 & 12 & 1.44 & 5 & 0.67 & 8 & 1.26 \\
\hline $\begin{array}{l}\text { Protein kinase } \\
\text { inhibitors }\end{array}$ & $\begin{array}{l}\text { Gefitinib, erlotinib, } \\
\text { sunitinib }\end{array}$ & 0 & 0.00 & 29 & 3.49 & 23 & 3.10 & 52 & 8.20 \\
\hline $\begin{array}{l}\text { Other targeted } \\
\text { therapies }\end{array}$ & Bortezomib & 0 & 0.00 & 0 & 0.00 & 4 & 0.54 & 4 & 0.63 \\
\hline Alkylating agents & & 182 & 25.74 & 255 & 30.65 & 200 & 26.99 & 181 & 28.55 \\
\hline $\begin{array}{l}\text { Nitrogen mustard } \\
\text { analogues }\end{array}$ & $\begin{array}{l}\text { Cyclophosphamide, } \\
\text { chlorambucil, } \\
\text { melphalan, ifosfamide }\end{array}$ & 146 & 20.65 & 216 & 25.96 & 147 & 19.84 & 133 & 20.98 \\
\hline Nitrosoureas & Carmustine & 0 & 0.00 & 0 & 0.00 & 3 & 0.40 & 3 & 0.47 \\
\hline $\begin{array}{l}\text { Other alkylating } \\
\text { agents }\end{array}$ & $\begin{array}{l}\text { Temozolomide, } \\
\text { dacarbazine }\end{array}$ & 36 & 5.09 & 39 & 4.69 & 50 & 6.75 & 45 & 7.10 \\
\hline Antimetabolites & & 154 & 21.78 & 119 & 14.30 & 124 & 16.73 & 146 & 23.03 \\
\hline $\begin{array}{l}\text { Folic acid } \\
\text { analogues }\end{array}$ & $\begin{array}{l}\text { Methotrexate, } \\
\text { pemetrexed }\end{array}$ & 42 & 5.94 & 26 & 3.13 & 39 & 5.26 & 44 & 6.94 \\
\hline $\begin{array}{l}\text { Pyrimidine } \\
\text { analogues }\end{array}$ & $\begin{array}{l}\text { Cytarabine, fluorouracil, } \\
\text { tegafur, gemcitabine, } \\
\text { tegafur+uracil }\end{array}$ & 112 & 15.84 & 93 & 11.18 & 85 & 11.47 & 102 & 16.09 \\
\hline $\begin{array}{l}\text { Plant alkaloids and } \\
\text { other natural } \\
\text { products }\end{array}$ & & 125 & 17.68 & 148 & 17.79 & 140 & 18.89 & 90 & 14.20 \\
\hline $\begin{array}{l}\text { Vinca alkaloids } \\
\text { and analogues }\end{array}$ & $\begin{array}{l}\text { Vinblastine, vincristine, } \\
\text { vinorelbine }\end{array}$ & 62 & 8.77 & 96 & 11.54 & 71 & 9.58 & 61 & 9.62 \\
\hline $\begin{array}{l}\text { Podophyllotoxin } \\
\text { derivatives }\end{array}$ & Etoposide & 54 & 7.64 & 52 & 6.25 & 63 & 8.50 & 29 & 4.57 \\
\hline Taxanes & Paclitaxel, docetaxel & 9 & 1.27 & 0 & 0.00 & 6 & 0.81 & 0 & 0.00 \\
\hline $\begin{array}{l}\text { Cytotoxic antibiotics } \\
\text { and related } \\
\text { substances }\end{array}$ & & 146 & 20.65 & 173 & 20.79 & 112 & 15.11 & 71 & 11.20 \\
\hline Actinomycines & Dactinomycin, & 5 & 0.71 & 0 & 0.00 & 0 & 0.00 & 0 & 0.00 \\
\hline $\begin{array}{l}\text { Anthracyclines and } \\
\text { related substances }\end{array}$ & $\begin{array}{l}\text { Doxorubicin, epirubicin, } \\
\text { idarubicin }\end{array}$ & 43 & 6.08 & 66 & 7.93 & 51 & 6.88 & 24 & 3.79 \\
\hline $\begin{array}{l}\text { Other cytotoxic } \\
\text { antibiotics }\end{array}$ & Bleomycin, mitomycin C & 98 & 13.86 & 107 & 12.86 & 61 & 8.23 & 47 & 7.41 \\
\hline Other agents & & 89 & 12.59 & 96 & 11.54 & 133 & 17.95 & 82 & 12.93 \\
\hline $\begin{array}{l}\text { Platinum } \\
\text { compounds }\end{array}$ & Cisplatin, carboplatin & 89 & 12.59 & 96 & 11.54 & 133 & 17.95 & 82 & 12.93 \\
\hline
\end{tabular}

\section{RESULTS}

Overall, alkylating agents had the highest yearly market share from 2009 to 2012 (range 25.74-30.65\%; table 1), followed by antimetabolites (range $14.30-23.03 \%$ ), and plant alkaloids and other natural products (range 14.20$18.89 \%$ ). Over this period, use of cytotoxic antibiotics and related substances decreased from $20.65 \%$ of market share in 2009 to $11.20 \%$ in 2012 , while other agents remained steady from $12.59 \%$ in 2009 to $12.93 \%$ in 2012. Notably, market share for targeted therapies, overall, grew rapidly from $1.56 \%$ in 2009 to $10.09 \%$ in 2012. Specifically, use of rituximab (the only monoclonal antibody) was stable over time (from $1.56 \%$ in 2009 to $1.26 \%$ in 2012). Protein kinase inhibitors (gefitinib, erlotinib and sunitinib) accounted for $3.49 \%$ of the market in 2010, which increased to $8.20 \%$ in 2012. Bortezomib use was low during the study period: $0.54 \%$ of the market in 2011, and $0.63 \%$ in 2012 .

Table 2 presented the trend in yearly costs for all and each type of antineoplastic drugs for treatment of eye cancer during 2009-2012. There was a large fluctuation for the total cost (between US\$60 968 and US\$99 455 per year) of all antineoplastic agents across years. Similar to their market share by prescription volume, 
Table 2 Trends in proportion of costs for antineoplastic agents for eye cancer in Taiwan by drug class

\begin{tabular}{|c|c|c|c|c|c|c|c|c|c|}
\hline \multirow[b]{3}{*}{ Drug class } & \multirow[b]{3}{*}{ Drug names } & \multicolumn{8}{|c|}{ Cost (US\$) } \\
\hline & & \multicolumn{2}{|c|}{2009} & \multicolumn{2}{|l|}{2010} & \multicolumn{2}{|l|}{2011} & \multicolumn{2}{|l|}{2012} \\
\hline & & Cost & $(\%)$ & Cost & $(\%)$ & Cost & $(\%)$ & Cost & $(\%)$ \\
\hline All antineoplastic agents & & 60968 & 100.00 & 95335 & 100.00 & 75006 & 100.00 & 99455 & 100.00 \\
\hline Targeted therapies & & 9218 & 15.12 & 33927 & 35.59 & 20732 & 27.64 & 58559 & 58.88 \\
\hline Monoclonal antibodies & Rituximab & 9218 & 15.12 & 9506 & 9.97 & 5034 & 6.71 & 7372 & 7.41 \\
\hline Protein kinase inhibitors & $\begin{array}{l}\text { Gefitinib, erlotinib, } \\
\text { sunitinib }\end{array}$ & 0 & 0.00 & 24422 & 25.62 & 15672 & 20.89 & 45034 & 45.28 \\
\hline $\begin{array}{l}\text { Other targeted } \\
\text { therapies }\end{array}$ & Bortezomib & 0 & 0.00 & 0 & 0.00 & 26 & 0.03 & 6152 & 6.19 \\
\hline Alkylating agents & & 15791 & 25.90 & 17232 & 18.08 & 17174 & 22.90 & 22482 & 22.61 \\
\hline $\begin{array}{l}\text { Nitrogen mustard } \\
\text { analogues }\end{array}$ & $\begin{array}{l}\text { Cyclophosphamide, } \\
\text { chlorambucil, } \\
\text { melphalan, ifosfamide }\end{array}$ & 7763 & 12.73 & 11343 & 11.90 & 8727 & 11.63 & 8580 & 8.63 \\
\hline Nitrosoureas & Carmustine & 0 & 0.00 & 0 & 0.00 & 360 & 0.48 & 0 & 0.00 \\
\hline Other alkylating agents & $\begin{array}{l}\text { Temozolomide, } \\
\text { dacarbazine }\end{array}$ & 8028 & 13.17 & 5889 & 6.18 & 8087 & 10.78 & 13902 & 13.98 \\
\hline Antimetabolites & & 4324 & 7.09 & 17522 & 18.38 & 16399 & 21.86 & 9395 & 9.45 \\
\hline Folic acid analogues & $\begin{array}{l}\text { Methotrexate, } \\
\text { pemetrexed, }\end{array}$ & 160 & 0.26 & 7109 & 7.46 & 12070 & 16.09 & 3684 & 3.70 \\
\hline Pyrimidine analogues & $\begin{array}{l}\text { Cytarabine, fluorouracil, } \\
\text { tegafur (=ftorafur), } \\
\text { gemcitabine, tegafur } \\
\text { +uracil }\end{array}$ & 4164 & 6.83 & 10413 & 10.92 & 4329 & 5.77 & 5712 & 5.74 \\
\hline $\begin{array}{l}\text { Plant alkaloids and other } \\
\text { natural products }\end{array}$ & & 16302 & 26.74 & 10784 & 11.31 & 7092 & 9.45 & 2052 & 2.06 \\
\hline $\begin{array}{l}\text { Vinca alkaloids and } \\
\text { analogues }\end{array}$ & $\begin{array}{l}\text { Vinblastine, vincristine, } \\
\text { vinorelbine }\end{array}$ & 1052 & 1.73 & 6013 & 6.31 & 614 & 0.82 & 969 & 0.97 \\
\hline $\begin{array}{l}\text { Podophyllotoxin } \\
\text { derivatives }\end{array}$ & Etoposide & 7873 & 12.91 & 4771 & 5.00 & 2389 & 3.19 & 1083 & 1.09 \\
\hline Taxanes & Paclitaxel, docetaxel & 7378 & 12.10 & 0 & 0.00 & 4089 & 5.45 & 0 & 0.00 \\
\hline $\begin{array}{l}\text { Cytotoxic antibiotics and } \\
\text { related substances }\end{array}$ & & 9876 & 16.20 & 10938 & 11.47 & 7590 & 10.12 & 3202 & 3.22 \\
\hline Actinomycines & Dactinomycin, & 44 & 0.07 & 0 & 0.00 & 0 & 0.00 & 0 & 0.00 \\
\hline $\begin{array}{l}\text { Anthracyclines and } \\
\text { related substances }\end{array}$ & $\begin{array}{l}\text { Doxorubicin, epirubicin, } \\
\text { idarubicin }\end{array}$ & 8495 & 13.93 & 9198 & 9.65 & 7094 & 9.46 & 2383 & 2.40 \\
\hline $\begin{array}{l}\text { Other cytotoxic } \\
\text { antibiotics }\end{array}$ & Bleomycin, mitomycin C & 1338 & 2.19 & 1740 & 1.82 & 496 & 0.66 & 818 & 0.82 \\
\hline Other agents & & 5456 & 8.95 & 4932 & 5.17 & 6020 & 8.03 & 3765 & 3.79 \\
\hline Platinum compounds & Cisplatin, carboplatin & 5456 & 8.95 & 4932 & 5.17 & 6020 & 8.03 & 3765 & 3.79 \\
\hline
\end{tabular}

alkylating agents accounted for around $23 \%$ of costs for antineoplastic drugs and remained stable during the study period. The proportion of costs for antimetabolites increased sharply in 2010 and 2011, but dropped back to $9.45 \%$ in 2012 . Unlike the stable trend in use by prescription volume, the proportion of costs for plant alkaloids and other natural products declined dramatically from $26.74 \%$ in 2009 to $2.06 \%$ in 2012. Proportion of costs for cytotoxic antibiotics and related substances fell from $16.2 \%$ in 2009 to $3.22 \%$ in 2012, similar to the decline in their market share over this period. Other antineoplastic agents accounted for a decreasing proportion of costs, which declined from $8.95 \%$ in 2009 to $3.79 \%$ in 2012 . The proportion of costs for targeted therapies overall grew dramatically from $15.12 \%$ in 2009 to $58.88 \%$ in 2012. Specifically, the proportion of costs for rituximab reduced from $15.12 \%$ in 2009 to $7.41 \%$ in 2012. Protein kinase inhibitors accounted for $25.62 \%$ of total costs for antineoplastic drugs in 2010, which increased to $45.28 \%$ in 2012. Bortezomib accounted for only $0.03 \%$ in 2011, but increased to $6.19 \%$ in 2012.

The quarterly market share by prescription volume for targeted therapies rose rapidly from $3.36 \%$ in the first quarter of 2009 to $17.33 \%$ in the fourth quarter of 2012 , and it was predicted to reach $27.33 \%$ in the fourth quarter of 2016 (table 3). Figure 1 shows the past trend and forecast of market share by prescription volume for targeted therapies for treatment of eye cancer during the study period. In terms of costs, the quarterly proportion of costs for targeted therapies among all antineoplastic drugs gradually grew from $35.15 \%$ in the first 
Table 3 Trends (2009-2012) and forecast (2013-2016) of market share by prescription volume and proportion of costs for targeted therapies among antineoplastic agents for eye cancer in Taiwan

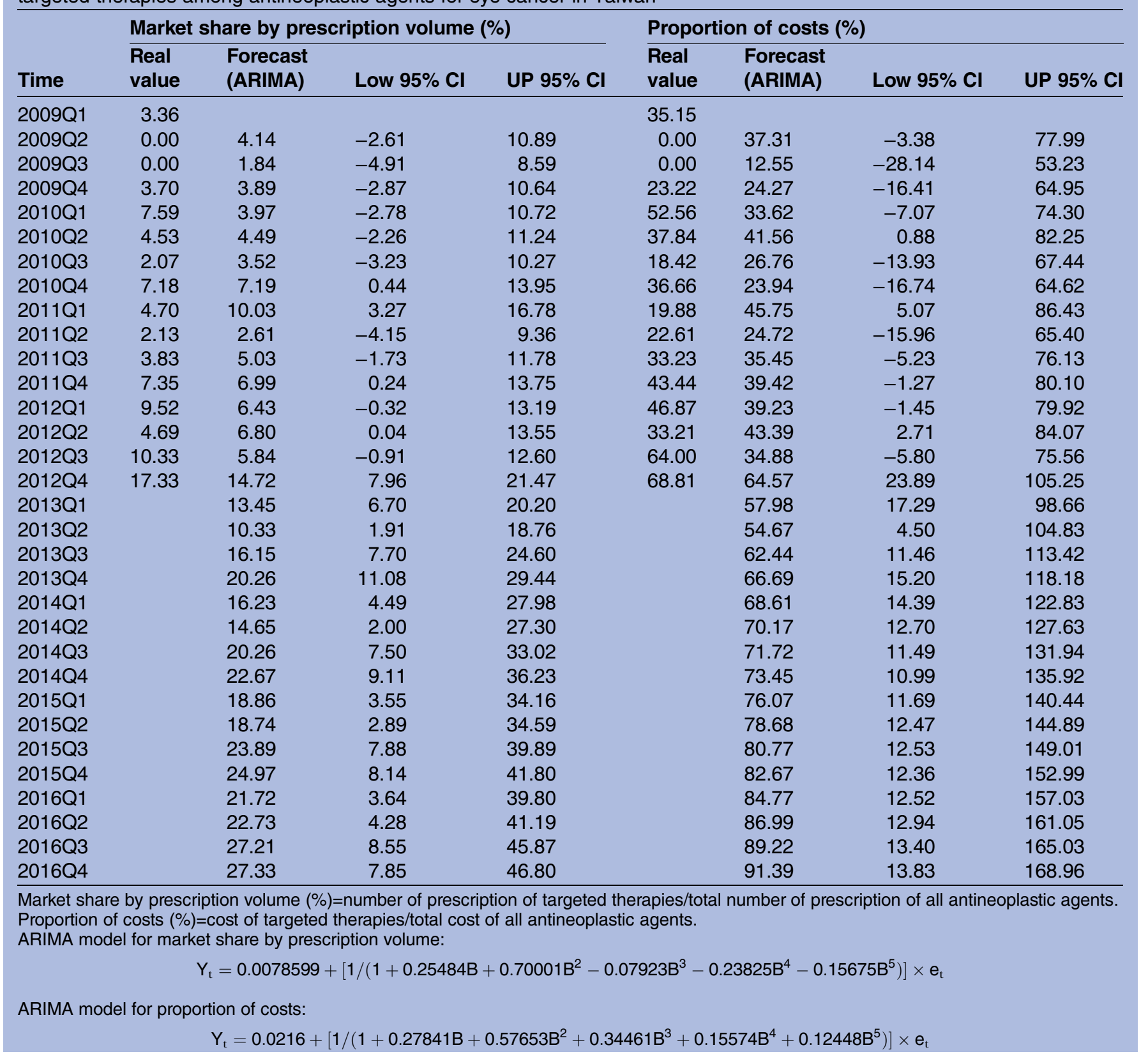

quarter of 2009 to $68.81 \%$ in the fourth quarter of 2012 , and it was predicted to reach $91.39 \%$ in the fourth quarter of 2016 (table 3). Figure 2 shows the past trend and forecast of proportion of costs for targeted therapies for treatment of eye cancer during the study period. Estimations of ARIMA models are reported in the online supplementary appendix.

\section{DISCUSSION}

This is the first study that reviewed and forecasted the time trend in use and costs of medications for treatment of eye malignancies in Taiwan. Our findings indicated that, compared with other classes of drugs, the new generation of antineoplastic agents (targeted therapies: rituximab, gefitinib, erlotinib, sunitinib, bortezomib) have become a relevant therapeutic quantity among eye malignancies in Taiwan, and they are likely to be used more commonly for eye cancer and other cancers in the future.

Between 2009 and 2012, use and costs of targeted therapies for eye cancer treatment increased almost sixfold, with protein kinase inhibitors (gefitinib, erlotinib and sunitinib) being the main drivers of such increase. Compared with only using traditional chemotherapy agents, treatments with targeted therapies or combination of treatments involving targeted therapies (eg, targeted therapies with chemotherapy agents, 
Figure 1 Trend (2009-2012) and forecast (2013-2016) of market share by prescription volume of targeted therapies among antineoplastic agents for eye cancer in Taiwan. *Market share $(\%)=$ number of prescription of targeted therapies/total number of prescription of all antineoplastic agents.

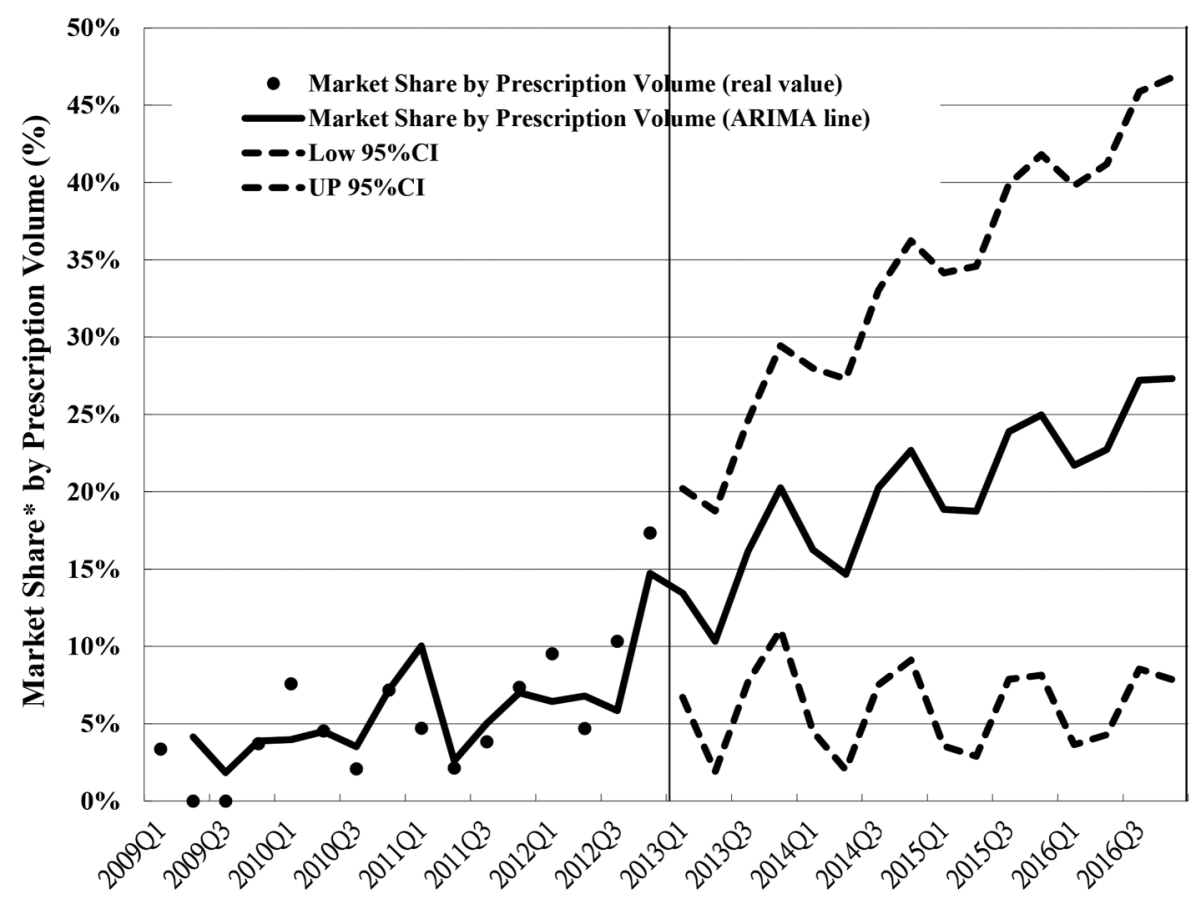

Time radiation and/or surgery) have been shown to improve quality of cancer care ( partly because of less toxicity and adverse effects $)^{20}$ and survival in some non-eye cancers. ${ }^{38} 39$ For instance, trastuzumab is becoming the main treatment for early stage and metastatic breast cancer. $^{4041}$ Furthermore, promising data have also been published for some eye cancer entities such as ocular adnexal lymphoma. 2042

Our findings showed that the use of targeted therapies is increasingly becoming an enormous economic burden for treatment of eye cancer due to their high costs. While targeted therapies only accounted for $10 \%$ of the market by prescription volume in 2012, they accounted for about $60 \%$ of costs of antineoplastic drugs, and we predicted that their use would reach $27 \%$ with over $90 \%$ of costs by the end of 2016 if the current trend continued. Therefore, the availability and increasing use of innovative but more expensive targeted therapies are major drivers of increases in pharmaceutical expenditures for eye cancer treatment. ${ }^{24} 25$ Given that the majority of costs for antineoplastic drugs for eye cancer treatments went to targeted therapies, and that
Figure 2 Trend (2009-2012) and forecast (2013-2016) of proportion of costs for targeted therapies among antineoplastic agents for eye cancer in Taiwan. *Proportion of costs (\%)=cost of targeted therapies/total cost of all antineoplastic agents.

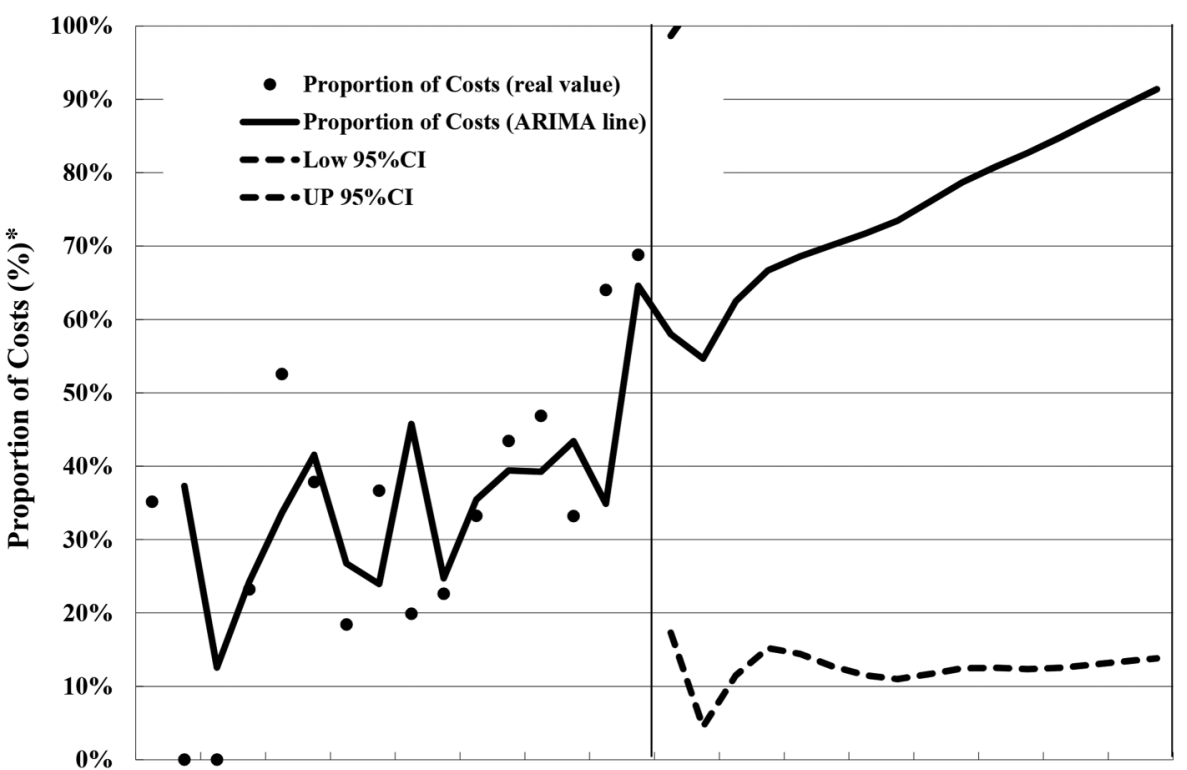

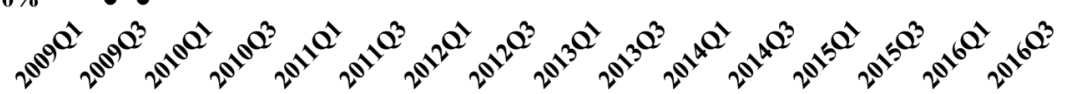

Time 
the upward trend is likely to continue, efforts need to focus on ensuring appropriate use of these expensive medications.

Many countries have implemented various policies to contain high prices and rising pharmaceutical expenditures of cancer drugs. For instance, many payers/policy makers assess cost-effectiveness evidence of new technologies against existing treatments in making coverage decisions. ${ }^{26}$ Many cancer drugs lack acceptable costeffectiveness evidence, but access may be enabled through patient access schemes (also known as managed entry or risk-sharing arrangements) in some countries. Given the high prices, even if they demonstrate only improvements in progression-free survival without marked gains in overall survival, ${ }^{21-23} 27-29$ pricing of new anticancer drugs is a real concern for accessibility and affordability across all countries. ${ }^{29} 4344$ The high cost of targeted therapies may continue to be a barrier to access for patients with eye cancer. ${ }^{45}{ }^{46}$ In Taiwan, prior authorisation and/or higher out-of-pocket costs by patients have been used for targeted therapies to relieve some economic burden for the national health system.

There are some limitations to this study. First, this study aimed to examine the current trends in drug usage and expenditures of treatments for eye malignancies in Taiwan, and to predict use and costs of targeted therapies in the near future. We did not analyse the associations between patient and prescriber characteristics, and treatment selection and subsequent clinical outcomes of treatments. Apart from their high costs, other factors that may influence the use of targeted therapies for treatment of eye cancer and clinical outcomes include the availability of individual targeted therapy, the publication of results of major randomised clinical trials, changes in clinical guidelines, or insurance reimbursement policies, patient characteristics and preferences, physician's knowledge and behaviours, and differences in risks and benefits between individualtargeted therapies. These should be examined in future studies. Second, this study did not examine use and costs of antineoplastic agents (including targeted therapies) for specific types of eye cancer because of the lack of complete information regarding the diagnosis of specific eye cancer classification. Third, the predicted values of market share and proportion of costs for targeted therapies were estimated by economic simulation method (time series design with ARIMA models) and based on the current patterns, the estimations might not represent the future real values. Finally, we did not examine clinical outcomes of cancer treatments. Whether increased use of targeted therapies is translated to improved patient outcomes should be rigorously studied.

\section{CONCLUSION}

This study examined national trends in use and costs of antineoplastic agents for treatment of eye cancer in
Taiwan during 2009-2012 with a focus on innovative targeted therapies, and we predicted future use and costs by econometric modelling. We found that targeted therapies constitute a more and more relevant proportion among all antineoplastic agents for eye cancer treatment in Taiwan, and they are a major economic burden. With targeted therapies which accounted for $10 \%$ of the antineoplastic agents market, but $60 \%$ of costs for eye cancer treatment in 2012, and with the upward trend that is likely to continue, efforts need to focus on ensuring appropriate use of these expensive medications, and research should examine patient outcomes.

Contributors $\mathrm{JCH}$ designed the study, collected data, performed analysis and drafted the manuscript. CYL reviewed all data and revised the manuscript critically for intellectual content. All authors approved the final version for submission.

Funding This research received no specific grant from any funding agency in the public, commercial or not-for-profit sectors.

Competing interests None declared.

Ethics approval National Cheng Kung University Hospital.

Provenance and peer review Not commissioned; externally peer reviewed.

Data sharing statement We obtained nationwide, monthly claims data for eye malignancy-related antineoplastic agents between 2009 and 2012 from the Taiwan National Health Insurance Research database (NHIRD). NHIRD does not permit external sharing of any of the data elements.

Open Access This is an Open Access article distributed in accordance with the Creative Commons Attribution Non Commercial (CC BY-NC 4.0) license, which permits others to distribute, remix, adapt, build upon this work noncommercially, and license their derivative works on different terms, provided the original work is properly cited and the use is non-commercial. See: http:// creativecommons.org/licenses/by-nc/4.0/

\section{REFERENCES}

1. Devesa SS, Silverman DT, Young JL Jr, et al. Cancer incidence and mortality trends among whites in the United States, 1947-84. J Natl Cancer Inst 1987;79:701-70.

2. Foss AJ, Dolin PJ. Trends in eye cancer mortality among adults in the USA and England and Wales. Br J Cancer 1996;74:1687-9.

3. Cheng CY, Hsu WM. Incidence of eye cancer in Taiwan: an 18-year review. Eye (Lond) 2004;18:152-8.

4. Mahoney MC, Burnett WS, Majerovics A, et al. The epidemiology of ophthalmic malignancies in New York State. Ophthalmology 1990;97:1143-7.

5. Swanson MW, Cloud G. A retrospective analysis of primary eye cancer at the University of Alabama at Birmingham 1958-1988. Part I: eye and orbital cancer. J Am Optom Assoc 1991;62:815-19.

6. Greenwald MJ, Strauss LC. Treatment of intraocular retinoblastoma with carboplatin and etoposide chemotherapy. Ophthalmology 1996;103:1989-97.

7. Morley M, Finger PT, Perlin M, et al. Cis-platinum chemotherapy for ocular basal cell carcinoma. Br J Ophthalmol 1991;75: 407-10.

8. Shields JA, Shields CL, De Potter $P$, et al. Diagnosis and treatment of uveal melanoma. Semin Oncol 1996;23:763-7.

9. Walton RC, Ellis GSJr, Haik BG. Rhabdomyosarcoma presumed metastatic to the orbit. Ophthalmology 1996;103:1512-16.

10. White L. Chemotherapy for retinoblastoma: where do we go from here? A review of published literature and meeting abstracts, including discussions during the Vth International Symposium on Retinoblastoma, October 1990. Ophthalmic Paediatr Genet 1991;12:115-30.

11. Wilson MW, Czechonska G, Finger PT, et al. Chemotherapy for eye cancer. Surv Ophthalmol 2001;45:416-44.

12. Shields CL, Bianciotto CG, Jabbour $P$, et al. Intra-arterial chemotherapy for retinoblastoma: report No. 1, control of retinal 
tumors, subretinal seeds, and vitreous seeds. Arch Ophthalmol 2011;129:1399-406.

13. Shields CL, Bianciotto CG, Jabbour $P$, et al. Intra-arterial chemotherapy for retinoblastoma: report No. 2, treatment complications. Arch Ophthalmol 2011;129:1407-15

14. Eagle RC Jr, Shields CL, Bianciotto C, et al. Histopathologic observations after intra-arterial chemotherapy for retinoblastoma. Arch Ophthalmol 2011;129:1416-21.

15. Wilson MW, Haik BG, Dyer MA. Superselective intraophthalmic artery chemotherapy: what we do not know. Arch Ophthalmol 2011;129:1490-1.

16. Rizzuti AE, Dunkel IJ, Abramson DH. The adverse events of chemotherapy for retinoblastoma: what are they? Do we know? Arch Ophthalmol 2008;126:862-5.

17. Abramson DH, Dunkel IJ, Brodie SE, et al. A phase I/II study of direct intraarterial (ophthalmic artery) chemotherapy with melphalan for intraocular retinoblastoma initial results. Ophthalmology 2008;115:1398-404. 1404.e1

18. Manjandavida FP, Honavar SG, Reddy VA, et al. Management and outcome of retinoblastoma with vitreous seeds. Ophthalmology 2014;121:517-24

19. Chen YH, Lin HY, Hsu WM, et al. Retinoblastoma in Taiwan: incidence and survival characteristics from 1979 to 2003. Eye (Lond) 2010;24:318-22.

20. Mok TS, Wu YL, Thongprasert S, et al. Gefitinib or carboplatin-paclitaxel in pulmonary adenocarcinoma. N Engl J Med 2009;361:947-57.

21. Lu CY, Cohen JP. Can genomic medicine improve financial sustainability of health systems? Mol Diagn Ther 2015;19:71-7.

22. Lu CY, Williams K, Day R, et al. Access to high cost drugs in Australia. BMJ 2004:329:415-16.

23. Hall WD, Ward R, Liauw WS, et al. Tailoring access to high cost, genetically targeted drugs. Med J Aust 2005;182:607-8.

24. Karaca-Mandic P, McCullough JS, Siddiqui MA, et al. Impact of new drugs and biologics on colorectal cancer treatment and costs. J Oncol Pract 2011;7(Suppl 3):e30s-37s.

25. Warren JL, Yabroff KR, Meekins A, et al. Evaluation of trends in the cost of initial cancer treatment. $J$ Natl Cancer Inst 2008;100:888-97.

26. Lu CY, Lupton C, Rakowsky S, et al. Patient access schemes in Asia-pacific markets: current experience and future potential. J Pharm Policy Pract 2015;8:6.

27. Godman B, Malmström RE, Diogene E, et al. Are new models needed to optimize the utilization of new medicines to sustain healthcare systems?. Expert Rev Clin Pharmacol 2015;8:77-94.

28. Mullard A. 2011 FDA drug approvals. Nat Rev Drug Discov 2012;11:91-4.

29. Kantarjian HM, Fojo T, Mathisen M, et al. Cancer drugs in the United States: Justum Pretium--the just price. J Clin Oncol 2013;31:3600-4.

30. Insurance BoNH. National Health Insurance Annual Statistical Report. October 2004. http://www.nhi.gov.tw/Resource/webdata/ Attach_8661_1_s92.pdf (accessed 8 Jun 2011).
31. Liu SZ, Romeis JC. Assessing the effect of Taiwan's outpatient prescription drug copayment policy in the elderly. Med Care 2003;41:1331-42.

32. Hsu JC, Lu CY, Wagner AK, et al. Impacts of drug reimbursement reductions on utilization and expenditures of oral antidiabetic medications in Taiwan: an interrupted time series study. Health Policy 2014;116:196-205.

33. Hsu JC, Ross-Degnan D, Wagner AK, et al. Utilization of oral antidiabetic medications in Taiwan following strategies to promote access to medicines for chronic diseases in community pharmacies. J Pharm Policy Pract 2015;8:15.

34. Mills TC. Time series techniques for economists. Cambridge University Press, 1990

35. Asteriou DH, Stephen G. ARIMA Models and the Box-Jenkins methodology, applied econometrics. 2nd edn. Palgrave MacMillan, 2011:265-86.

36. Hsu JC, Ross-Degnan D, Wagner AK, et al. How Did Multiple FDA actions affect the utilization and reimbursed costs of thiazolidinediones in US medicaid? Clin Ther 2015;37: 1420-32.e1.

37. Lu CY, Emmerick IC, Stephens $P$, et al. Uptake of new antidiabetic medications in three emerging markets: a comparison between Brazil, China and Thailand. J Pharm Policy Pract 2015;8:7.

38. Köhne $\mathrm{CH}$, Lenz $\mathrm{HJ}$. Chemotherapy with targeted agents for the treatment of metastatic colorectal cancer. Oncologist 2009;14:478-88.

39. Mahalingam D, Mita A, Mita MM, et al. Targeted therapy for advanced non-small cell lung cancers: historical perspective, current practices, and future development. Curr Probl Cancer 2009;33:73-111.

40. Lu CY, Srasuebkul P, Drew AK, et al. Trastuzumab therapy in Australia: which patients with HER2+ metastatic breast cancer are assessed for cardiac function? Breast 2013;22:482-7.

41. Lu CY, Srasuebkul P, Drew AK, et al. Positive spillover effects of prescribing requirements: increased cardiac testing in patients treated with trastuzumab for HER2+ metastatic breast cancer. Intern Med J 2012;42:1229-35.

42. Shome D, Esmaeli B. Targeted monoclonal antibody therapy and radioimmunotherapy for lymphoproliferative disorders of the ocular adnexa. Curr Opin Ophthalmol 2008;19:414-21.

43. Howard DH, Bach PB, Berndt ER, et al. Pricing in the market for anticancer drugs. J Econ Perspect 2015;29:139-62.

44. Ghinea N, Kerridge I, Lipworth W. If we don't talk about value, cancer drugs will become terminal for health systems. The Conversation. 2015. https://theconversation.com/if-we-dont-talkabout-value-cancer-drugs-will-become-terminal-for-healthsystems -44072

45. O'Dowd A. Watchdog set to reject four drugs for kidney cancer on the NHS. BMJ 2008;337:a1262.

46. Wahlstera P, Scahillb S, Lu CY, et al. Barriers to access and use of high cost medicines: a review. Health Policy Technol 2015;4:191-214. 